\title{
Understanding and addressing barriers to successful adenovirus-based virotherapy for ovarian cancer
}

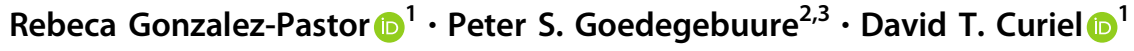

Received: 16 June 2020 / Accepted: 9 September 2020 / Published online: 19 September 2020

(c) The Author(s), under exclusive licence to Springer Nature America, Inc. 2020

\begin{abstract}
Ovarian cancer is the leading cause of death among women with gynecological cancer, with an overall 5-year survival rate below $50 \%$ due to a lack of specific symptoms, late stage at time of diagnosis and a high rate of recurrence after standard therapy. A better understanding of heterogeneity, genetic mutations, biological behavior and immunosuppression in the tumor microenvironment have allowed the development of more effective therapies based on anti-angiogenic treatments, PARP and immune checkpoint inhibitors, adoptive cell therapies and oncolytic vectors. Oncolytic adenoviruses are commonly used platforms in cancer gene therapy that selectively replicate in tumor cells and at the same time are able to stimulate the immune system. In addition, they can be genetically modified to enhance their potency and overcome physical and immunological barriers. In this review we highlight the challenges of adenovirus-based oncolytic therapies targeting ovarian cancer and outline recent advances to improve their potential in combination with immunotherapies.
\end{abstract}

\section{Ovarian cancer}

Ovarian cancer is the seventh most common cancer and the second cause of death among women with gynecological cancer (after that of the cervix uteri) [1]. Although incidence rates have declined since the mid-80s and mortality is falling an average of $2.3 \%$ each year [2], an estimated 21,750 new cases of ovarian cancer will be diagnosed in the US and 13,940 women will die from the disease in 2020. The overall 5-year survival rate is only $47 \%$, with more than $75 \%$ of patients diagnosed with advanced distant-stage disease (FIGO stage III/IV disease, 5-year survival rate of $29 \%$ ). For the $15 \%$ of patients diagnosed with early localized disease (FIGO stage I), 5-year survival is 92\% [3, 4]. Several factors add to the high morbidity and mortality

David T. Curiel

dcuriel@wustl.edu

1 The Division of Cancer Biology and Biologic Therapeutics Center, Department of Radiation Oncology, School of Medicine, Washington University in Saint Louis, 660 South Euclid Avenue, Campus Box 8224, St. Louis, MO 63110, USA

2 Department of Surgery, Washington University School of Medicine, Saint Louis, MO 63110, USA

3 Alvin J. Siteman Cancer Center, 660 S. Euclid Avenue, St. Louis, MO 63110, USA rates: late stage at time of diagnosis, a high rate of recurrence and hurdles to effective therapy for patients with advanced-stage disease and for those who relapse. Although the prognosis in cases detected at an early stage is quite favorable, organ-confined stage ovarian cancer has no obvious symptoms, and current methods for ovarian cancer screening, i.e., transvaginal ultrasonography and detection of serum cancer antigen (CA125), have demonstrated poor sensitivity at this stage. Together with the fact that the use of these screening methods did not show a significant mortality reduction, there is thus no available screening routine for the general population at the present time. Novel approaches based on the detection of specific circulating tumor DNA and miRNAs are under investigation, but those methods are not yet capable of detecting asymptomatic disease [5-7]. Even though chemotherapy is successful at the time of presentation, around $70 \%$ of patients have recurrence in the first 3 year, and $15 \%$ relapse with chemoresistant disease, that is not curable [8]. Most patients die from malignant bowel obstruction, which usually affects multiple sites and cannot be subjected to surgery $[9,10]$.

Ovarian cancer is not a single disease, but rather a general term for a heterogeneous group of neoplasms but with loco-regional dissemination to the ovary and pelvic organs. More than $90 \%$ of malignant ovarian tumors are epithelial in origin. Epithelial ovarian cancer (EOC) is further classified into five subtypes with different cellular origin, 
pathogenesis, molecular alterations, gene expression, and prognosis $[3,11]$. In particular, high-grade serous ovarian carcinoma (HGSOC) is the most aggressive and most common type of EOC, accounting for $75 \%$ of all deaths [12]. It originates in both ovarian surface epithelium and fallopian tube epithelium and typically presents as a large ovarian mass accompanied by widespread peritoneal metastasis and presence of ascites [13, 14].

In contrast to most carcinomas, dissemination of ovarian carcinoma through the vasculature is rare, which explains its confinement within the abdominal cavity. Ovarian cancer cells spread by direct extension to adjacent organs, and exfoliated tumor cells, either as single cells or as spheroids, freely disseminate throughout the peritoneal cavity by the peritoneal fluid and preferentially colonize the omentum, the diaphragm and the mesentery $[15,16]$. Metastatic tumors also seed in other organs of the peritoneum, but only invade the superficial layers of tissue $[17,18]$. In fact, the exfoliation capability from small masses difficults HGSOC screening [7]. Two key features of disease progression are the characteristic anoikis resistance of EOC cells and their ability to attach to the mesothelial cells covering the peritoneal organs $[17,19]$, a process where matrix metalloproteinases (MMP-2) and integrins ( $\alpha 5 \beta 1$ and $\alpha \mathrm{V} \beta 3)$ are largely involved [20-22].

Treatment guidelines for EOC have largely been driven by HGSOC, which is characterized by homologous recombination deficiency and harbor TP53 mutations, with lower prevalence but recurrent somatic mutations in BRCA1, BRCA2, NF1, RB1 and CDK12 [23, 24], even though it has been demonstrated that response to treatment varies by gene expression profiles [25, 26].

An overview of the treatment strategies developed for EOC over the past 30 years [27, 28], from standard chemotherapy to anti-angiogenic therapy, and the latest incorporation of poly (ADP Ribose) polymerase (PARP) inhibitors and immune checkpoint inhibitors, reveals that, although at a slower rate compared to other malignancies, increasing knowledge about genetic mutations and associated biological behavior are leading to the incorporation of the standard of care into the era of targeted therapy $[8,29]$. In this context, gene therapy, and in particular virotherapy [30], have explored different treatment opportunities and demonstrated encouraging preclinical results.

\section{Adenovirus-based oncolytic virotherapy}

Adenoviruses (Ad), in particular serotypes 2 and 5, are the most well-described and frequently used platforms for virotherapy applications. Their large packaging capacity, ability to infect both dividing and non-dividing cells, lack of integration into the host genome and the mild nature of illness after infection, are some of the many features that make them attractive for gene therapy [31-34]. In the context of cancer gene therapy, first clinical trials employing replication-incompetent adenoviruses demonstrated their potential to deliver and express the p53 tumor suppressor gene in ovarian cancer and other malignancies [35-41]. To overcome the limited efficacy and duration of transgene expression and at the same time diminish potential side effects, earlier efforts investigated the use of oncolytic Ads, which specifically replicate within tumor cells, ultimately killing them and spreading through the tumor and, potentially triggering the host's immune system $[42,43]$. Tumor selectivity is not a natural feature of adenoviruses, but advances in the knowledge of Ad biology and recombinant tools to manipulate their viral genomes facilitated engineering advanced conditionally replicative adenoviruses (CRAd) based on two general strategies [44]. One involves the insertion of tumor-specific promoters (TSP) into the viral genome to drive the expression of E1A gene, which initiates Ad replication. The other involves deleting parts of the E1A or E1B genes to prevent replication in normal cells, but enable replication in tumor cells with malfunctioning cellular transcriptional machinery. Relevant modifications involve the deletion of the E1B-55k gene ( $d l 1520 /$ Onyx-015) that prevents p53-mediated apoptosis and the deletion of the $\mathrm{Rb}$ protein binding site on E1A (dl922-947 and $\operatorname{Ad} \Delta 24)$ [45, 46], with E1Adeletion mutants having improved oncolytic efficacy compared to E1B mutants both in vitro and in vivo [47, 48]. In addition, by taking advance of cell cycle dysregulation, early generation oncolytic Ads show encouraging results in combination with standard chemotherapy in advanced and recurrent resistant disease [49-51].

Preclinical in vivo models that both accurately recapitulate human HGSOC and allow testing of oncolytic Ad vectors and their immunobiological effects are absent [52-54]. A focus of the last decade has been the search for immunocompetent animal models and humanized models accurately representative of EOC that contribute to decipher virus/host interactions, as studies to date mostly use human xenografts in immunodeficient mice. Although ID8 is the most studied murine syngeneic EOC model and improved derivatives have been developed [55-57], full replication of human Ad is limited to certain murine cell lines [58-61]. Syrian hamsters have been reported to support Ad5 replication [62], but no EOC models are available. Patientderived ex vivo tumor cultures of EOC have been used as an alternative to study Ad immune-modulation [63].

\section{Restricting adenoviral infection through transductional targeting}

The first clinical trials testing Ad virotherapy established insufficient targeting as one of the main reasons for failure. 
The entry of Ad5 into cells requires binding of the knob domain of the fiber protein with the high-affinity coxsackievirus and adenovirus receptor (CAR) and subsequent interaction between the arginine-glycine-aspartic acid (RGD) sequence of the penton and $\alpha v \beta 3$ and $\alpha v \beta 5$ integrins [64, 65]. Evidence demonstrated that CAR and integrins are expressed at low levels in many epithelial ovarian cancers and those levels are inversely related to tumor grade [66-68]. To circumvent CAR-dependent cell entry and improve tumor selectivity, Ad5 fiber has been modified by inserting peptide ligands selective for tumorassociated receptors in EOC cells [69]. It was demonstrated that the addition of an RGD motif or a polylysine (pk7) motif into the knob increases Ad5 binding to integrins or heparan sulfate proteoglycans (HSPGs), respectively, achieving improved level of gene transfer into EOC cell lines and primary tumors that were resistant to Ad5 infection, without affecting fiber function [70-72]. Combining an RGD motif in both the fiber and the capsid protein IX showed greater oncolytic activity in vitro, but no benefit in vivo [73]. Of particular relevance is Ad5$\Delta 24 \mathrm{RGD}$, which yielded positive results in vitro, complete eradication of intraperitoneal disease in a xenograft mouse model and promise in a phase I clinical trial of recurrent HGSOC [74-76]. Uusi-Kerttula et al showed moderate to up to 950-fold higher efficiency in the presence of neutralizing ovarian ascites when incorporating targeting peptides into the HI loop to either $\alpha \mathrm{v} \beta 6$ integrin (A20) [77] or epidermal growth factor (EGFR) (GE11) [78], both overexpressed in $30 \%$ EOC and suggested a correlation with disease progression.

Another strategy to improve adenoviral tropism via a CAR-independent pathway consists on replacing the knob of Ad5 (subgroup C) with alternative serotypes, mainly from species B and species D [79]. Chimeric Ad5/ 3 vector, which uses predominantly desmoglein-2 (DSG2) receptor but also CD46 receptor [80, 81], was confirmed to achieved higher infectivity in EOC cells and subcutaneous tumor xenograft after intratumoral injection than Ad5 and also the RGD variant, with a similar biodistribution profile [82, 83]. Moreover, Ad5/3- $\Delta 24$ demonstrated greater oncolytic effect compared to Ad5$\triangle 24 R G D$ in cell lines, clinical tumor samples and in a intraperitoneal xenograft murine model [84, 85], showing a good safety profile and potential in a phase I clinical trial [86]. In order to achieve higher transduction efficiency by using CD46, Hulin-Curtis et al pseudotyped Ad5 with the fiber of $\operatorname{Ad} 35$ [87, 88] and was able to achieve higher transduction efficiency in EOC cells. Similar to Ad5-A20, a chimeric Ad5/48-A20 vector based on the low seroprevalent Ad48 was able to target primary ex vivo cultures in the presence of neutralizing ovarian ascites [77].

\section{Restricting adenoviral replication}

In order to limit Ad replication to the target tissue, transcription of adenoviral genes, generally E1, can be controlled by TSPs. Early modifications include the cyclooxygenase-2 (cox-2) promoter, the secretory leukocyte protease inhibitor (SLPI) promoter and the vascular endothelial growth factor (VEGF) promoter. While Ad5RGD-Cox-2- $\Delta 24$ caused less toxicity to nonmalignant cells, VEGF tumor-specific promoter showed greater replication and no significant differences in vivo compared to Ad5-424RGD [89-91]. Similarly, Ad5/3-SLPI showed efficient viral replication and oncolysis and significantly decreased liver toxicity compared to Ad5/3Cox-2 or Ad5/ $3 \mathrm{wt}$, although no increased survival [92]. An Ad5 vector bearing the human telomerase reverse transcriptase (hTERT) promoter together with an Ad5/3 vector bearing the multidrug resistance gene 1 (MDR1) promoter were found to significantly enhance survival in combination with chemotherapy in cisplatin-resistant xenograft models with peritoneal dissemination [93, 94]. Several groups have validated the utility of the chemokine CXCR4 receptor as well as the Survivin promoter and the Mesothelin promoter to increase selectivity, improve oncolysis and decrease liver uptake in murine xenograft EOC models when included into Ad5/3 and Ad5-RGD vectors [95-98]. Increasing evidence indicates the important role of various types of stromal cells in TME in supporting tumor progression and highlight them as attractive targets $[99,100]$. In this context, Lopez et al described a stroma-targeted CRAd pseudotyped with chimeric fiber $5 / 3$ including a SPARC promoter fragment that was effective in the remission of disseminated HGSOC in nude mice and was able to replicate in fresh tumor explants [101]. In the same way, Long et al developed an adenovirus system based on Cre/LoxP and a CD133 promoter to target $\mathrm{CD}_{133^{+}}$ovarian cancer stem cells, which contribute to recurrence and chemoresistance, to increase apoptosis and suppress tumor growth [102].

\section{Increasing potency of CRAds}

Because CRAds are often unable to eliminate entire tumors by viral replication alone, they have been armed with suicide genes, transgenes that target the TME and immunomodulatory molecules to potentiate anti-tumor efficacy [103, 104]. It must be taken into consideration that the $\mathrm{Ad}$ genome has limited space and can accommodate up to $105 \%$ of the wildtype genome length without compromising viral assembly. In addition, the insert gene should be placed in a location that yields ideal expression and allows normal replication. The most extensively used transgenes for boosting cell killing are "suicide genes" that encode prodrug-converting enzymes and promote a "bystander 
effect", by which the cytotoxic metabolites generated diffusing into neighboring cells are also killed. In EOC, results reported when using the herpes simplex virus thymidine kinase/gancyclovir (HSV-TK/GCV) suggest that, although Ad5 and Ad5/3 vectors with E1A or E1B deletions containing the TK transgene were able to suppress tumor growth in subcutaneous and intraperitoneal xenograft tumor models, the addition of ganciclovir was effective only when the oncolytic potential of the CRAds was low [105-107]. The cytosine deaminase/5-fluorocytosine (CD/5FC) system included into an Ad vector reported promising results against EOC cells [108, 109]. Other groups included a manganese superoxide dismutase $(\mathrm{MnSO})$ transgene or a reverse activator of transcription-3 (STAT3) cDNA to enhance drug sensitivity in cisplatin-resistant HGSOC cells $[110,111]$.

The TME also consists of non-cellular components such as the extracellular matrix (ECM), ECM remodeling enzymes and growth factors, whose complex structure can act as a physical barrier that limits CRAds efficacy $[112,113]$. In order to facilitate viral spread, Yang et al incorporated the tissue inhibitor of metalloproteinase 2 (TIMP2) gene into Ad5/3-CXCR4 to target angiogenesis and tumor invasion and demonstrated more efficient and specific replication and oncolysis in a HGSOC ex vivo model compared to unarmed CRAds [114].

To enhance the activity of the immune system against the tumor, cytokines or chemokines can be locally expressed by oncolytic Ads, maximizing the anti-tumor effect against the primary tumor and potentially the metastasis and minimizing systemic toxicity. Construction of $\operatorname{Ad} 5 / 3 \Delta 24$ containing either IL-24 or ING4 revealed interference in CRAd propagation from ING4 expression but significantly enhanced oncolytic potency of CRAd-IL4 in vitro as compared to non-armed CRAd and CRAd-ING4 [115], although no improvements were seen in a subcutaneous xenograft murine model [61]. Different studies have sought to increase oncolytic activity and reduce acute immune stimulation during CRAd therapy by blocking the expression of TNF- $\alpha, \beta 3$ integrin or IL-8 [116-118], but this potentially limits the adaptive anti-tumor immune response $[43,119,120]$. Because $\mathrm{T}$ cells are not only generated against tumor cells but are also able to initiate a strong antiviral response, CRAd design and route of injection will influence the balance towards an anti-viral or anti-tumor response. While no differences in anti-tumor efficacy were seen between Ad5/3-E2F- $\Delta 24$ and Ad5/3-E2F- $\Delta 24$ hTNF $\alpha$-IRES-hIL2 in an immunocompromised model, the expression of the cytokines enhanced T cell recruitment and activation in an ex vivo EOC model and an immunocompetent model, demonstrating resistance to tumor recurrence [63, 121, 122]. Two oncolytic Ads based on $\operatorname{Ad} 5 \Delta 24$ and $\operatorname{Ad} 5 / 3 \Delta 24$ armed with granulocyte- macrophage colony stimulating factor (GMCSF) were capable of inducing both tumor- and virus-specific immunity, were well tolerated and demonstrated clinical benefits in some patients with refractory advanced solid tumors. In particular, administration of ONCOS-102 (Ad5/3 $\Delta 24$ GMCSF) showed induction of strong tumor-specific CD8+ $\mathrm{T}$ cells in tumors and systemically [123-126].

\section{Overcoming physical barriers to dissemination of oncolytic adenoviruses}

While the intraperitoneal confinement of HGSOC allows for localized delivery of CRAds and potentially bypass many restrictions associated with intravenous delivery and reduce toxicity [127, 128], this route can suffer from rapid Ad clearance and poor distribution if the cavity becomes loculated (Fig. 1). Ascites, a complex heterogeneous mixture consisting mainly of tumor cells, mesothelial cells, fibroblasts, immune cells, cytokines and growth factors, accumulate due to increased permeability of afferent vessels of the peritoneal lining and reduced lymphatic flow. In addition, high-volume ascites are likely to result in tumors with poor vascular delivery [129-131]. More importantly, neutralizing antibodies against $\mathrm{Ad} 5$ have been found in serum from healthy patients and in the ascites of HGSOC patients [132-134]. Additionally, host Ad sensing mechanisms activate proinflammatory signaling and promote long-term local inflammation and adhesion formation after intraperitoneal delivery [135].

The interactions impacting Ad biodistribution upon intravascular delivery have been widely described. Reasons for the low efficacy of Ad5-derived vectors include clearance after opsonization by natural antibodies and complement, as well as sequestration in the liver and spleen mediated by binding with human coagulation factor 10 (FX) and other coagulation factors to HSPG abundant on hepatocytes or scavenger receptors on Kupffer cells [136-138]. Since a small portion of the Ad particles injected ip are able to enter the circulation, Ad vectors administered through this route are susceptible to clearance after interacting with blood components and residential macrophages in tissue and in the peritoneal cavity $[83,139]$. It was first shown that modifications of the fiber partially ablate neutralization of the virus [77, 78, 84, 140], and later, that additional pseudotyping of the hexon or the ablation of FX binding sites in the hexon decreases liver sequestration, toxicity and vectorimmune system interactions in both ip and iv approaches [88, 141, 142]. Recently, Uusi-Kerttula et al combined triple detargeting through mutations on the fiber that block binding to CAR, the penton to block binding to $\alpha v \beta 3 / 5$ integrins, and the hexon for FX binding, with insertion of the A20 peptide into the HI loop [143]. Ad5NULL-A20 CRAd demonstrated high tumor selectivity, significant 
Fig. 1 Barriers to Ad vector delivery. Intraperitoneal administration of Ads into the complex biological environment of the peritoneal cavity can limit tumor transduction, favor heterogeneous distribution, rapid Ad aggregation and clearance and cytotoxicity. Genetic, chemical and physical modifications can be implemented to overcome these barriers, decrease detargeting and increase specific infection of EOC cells. L: liver, O: omentum, M: mesentery, T: tumor, ip: intraperitoneal, DC: dendritic cells, NK: natural killers.

reduction in off-target uptake and tumor-free survival in an EOC xenograft model compared to either Ad5 $\Delta 24$ or Ad5 $\Delta 24 . A 20$. In the context of Ad serotypes, Thoma et al observed that, while Ad5 induces long-term damage by promoting acute liver pathology, enlargement of the spleen and formation of severe adhesions, intraperitoneal injection of Ad11 only caused short-term mild inflammation due to macrophages controlling disproportionate inflammatory responses [135]. Based on the results obtained with Enadenotucirev (ColoAd1, chimeric Ad3/Ad11p) in colon cancer, two potent chimeric ColoAd1/Ad3 recombinant CRAds were isolated by directed evolution against platinum-resistant HGSOC that demonstrated potent and tumor selective activity in vitro and in vivo and absence of peritoneal adhesions [144]. Moreover, Enadenotucirev is currently being evaluated in a phase $1 / 2$ trial either alone or with paclitaxel.

Another approach shields the Ad from the immune system by chemically and physically modifying the capsid with polymers and liposomes [145-147]. Since the modifications are not carried into the Ad progeny, coating the vector might be more interesting when several administrations are required. Administration of a PEGylated liposomeencapsulated Ad expressing human endostatin or complexed with multiple layers of polyethylenimine (PEI) and hyaluronic acid (HA) increased survival and demonstrated better protective activity from host immune clearance [148, 149]. In addition to ablating Ad tropism, coating the vector can increase tumor retention by passive targeting and retargeting to alternative receptors. Lanciotti et al showed five-fold increase in the tumor and 10 times reduction in the liver and spleen of an Ad coated with PEG (polyethyleneglycol) functionalized with Fibroblast Growth Factor 2 (FGF2), along with less antibody neutralization

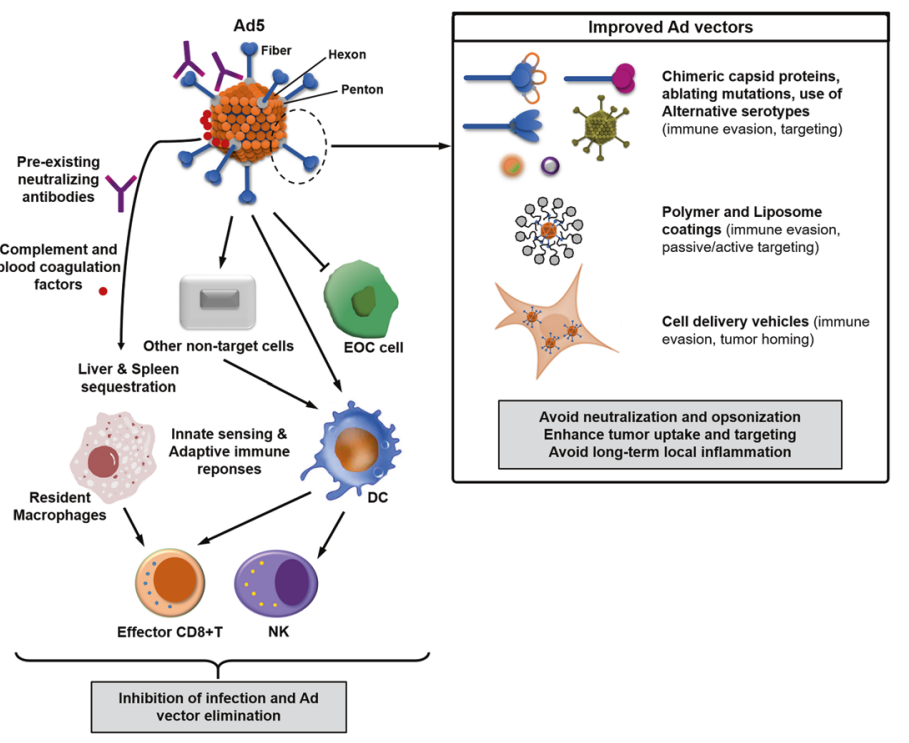

and $\mathrm{T}$ cell responses [150]. Morrison et al were able to protect the vector from neutralizing antibodies and demonstrated significantly lower tumor load and absence of inflammatory toxicities by coating Ad5 with poly (hydroxypropyl methacrylamide (pHPMA) and retargeting to EGFR with EGF or cetuximab [151, 152]. Thanks to their natural tumor tropism and immunomodulatory properties, mesenchymal stem cells (MSCs) of different origins have been used as carriers of oncolytic Ads [153-155], increasing targeted delivery and reducing the hepatic uptake and systemic toxicity seen in clinical trials of vectors such as Ad5- 2 24RGD [156]. Menstrual blood MSCs (MenSCs) were successfully used to deliver an Ad5/3 $\Delta 24$ CRAd with microenvironment-responsive elements and the SPARC promoter without being blocked by antibodies present in the ascites, which also contain soluble factors that can serve as transcriptional enhancers [157]. Mooney et al showed that neural stem cells (NSC) carrying an oncolytic Ad bearing the survivin promoter and polylysine peptide into the fiber (CRAd-S-pk7) were able to selectively penetrate HGSOC tumor metastases, allowing replication of the virus, and synergistically reduce tumor growth in combination with cisplatin [158].

\section{Overcoming immunosuppression}

Despite the success of immunotherapy in other malignancies, such as melanoma or lung cancer, and the promising results seen in preclinical models, results obtained with immune checkpoint inhibitors, cancer vaccines or adoptive cell transfer (ACT) in EOC have not been that positive $[9,28,159]$. It has been demonstrated that the mutational profile defines immunogenicity, meaning that HGSOC tumors with disrupt DNA repair mechanisms result 


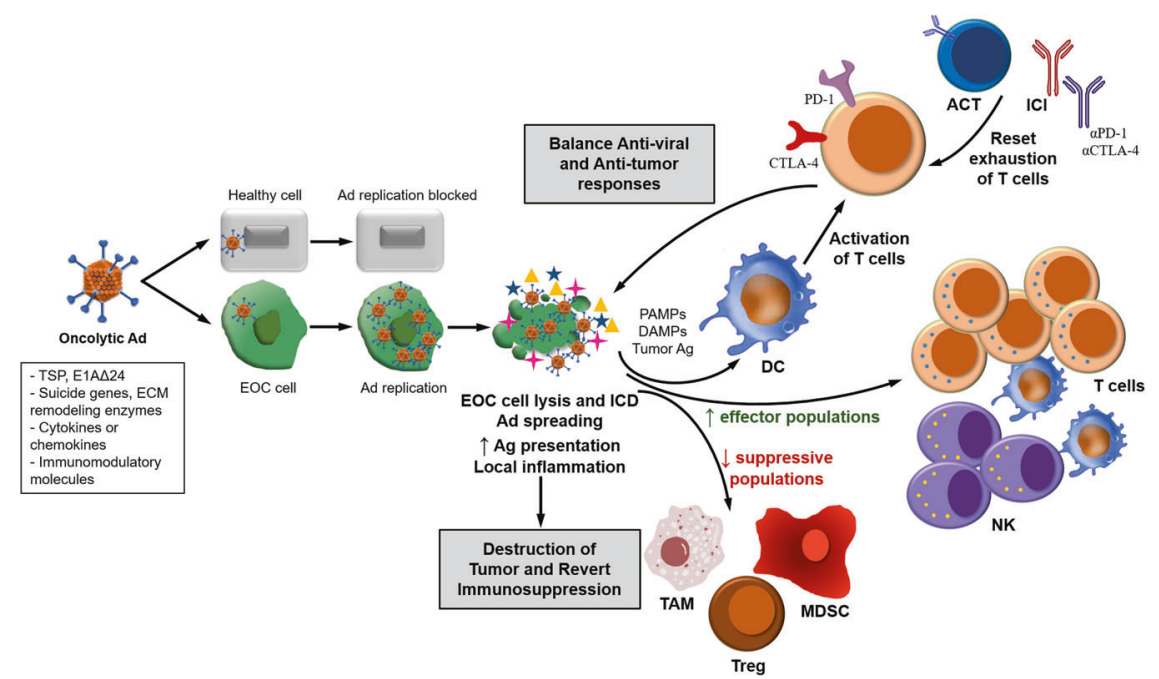

Fig. 2 Oncolytic Ads help overcoming immunosuppression and boosting anti-tumor immunity in EOC. Oncolytic Ads are genetically modified with tissue-specific promoters (TSP) and mutations on E1A to specifically replicate in and kill tumor cells. At the end of the lytic cycle, viral progeny spreads throughout the tumor, infecting and lysing surrounding cancer cells, facilitating the release of pathogen and danger associated molecular patterns (PAMPs and DAMPs) and tumor antigens (neoantigens and tumor associated antigens), together with the amplification of the expression of therapeutic transgenes in the

in higher mutational burden and neoantigen presence, which in turn increases CD3+ and CD8+ TILs, PD-1/PD-L1 expression, susceptibility to immune checkpoint therapy and survival. However, only a small percentage of mutations are recognized by autologous tumor-associated $\mathrm{T}$ cells, and tumor heterogeneity can limit expression of neoantigens to a small proportion of tumor cells. Although EOC express known, non-mutated tumor-associated antigens (TAAs), poor immunogenicity prevents appropriate TAA-mediated tumor rejection $[160,161]$. In addition, the TME in EOC is particularly immunosuppressive, not only in primary tumors but also in the ascites and in the omentum. While the omentum is a complex immunologic organ that actively and passively entraps EOC cells in its highly vascularized immunologic units known as milky spots, tumor-associated macrophages (TAMs), regulatory $\mathrm{T}$ cells (Treg) and myeloid derived suppressor cells (MDSCs), together with other components such as EOC-derived exosomes, cancer-associated fibroblasts (CAFs) and adipocytes, are involved in impairing both the presence and the activity of effector $\mathrm{T}$ cells, neutrophils and natural killer (NK) cells, and disease progression [162-165].

In order to generate a significant anti-tumor immune response, different combination strategies are under investigation based on priming $\mathrm{T}$ cell responses, inducing immunogenic cell death and targeting checkpoint inhibitors (PD1/PD-L1 and CTLA-4/CD80/CD86 pathways) responsible for $\mathrm{T}$ cell anergy and/or exhaustion [166, 167], tumor microenvironment. Oncolytic Ads promote strong antiviral innate responses and prime adaptive immune responses, facilitating the recruitment of effector cells, overcoming immunosuppression, and oncolytic Ads can be used in combination with immunotherapy approaches to prevent $\mathrm{T}$ cell exhaustion, successfully generating antitumor immunity. ECM: extracellular matrix, DC: dendritic cells, TAM: tumor-associated macrophages, Treg: regulatory $\mathrm{T}$ cells, MDSC: myeloid derived suppressor cells, NK: natural killers, ICI: immune checkpoint inhibitors, ACT: adoptive cell therapies.

depending on EOC immune status. In this context, oncolytic Ads represent a powerful tool to generate immunologically hot tumors, since by replicating and killing tumor cells, pathogen and danger associated molecular patterns (PAMPs and DAMPs), TAAs and tumor neoantigens are released, stimulating the immunomodulation of the TME, TIL recruitment, priming dendritic cells and tumor-specific T-cell responses and potentially generating memory responses [42, 168]. Different regimens of administration are being tested combining oncolytic Ads and CAR T therapy, adoptive TIL transfer and immune-checkpoint inhibitors to boost the anti-tumor activity [169] (Fig. 2).

In order to combine direct Ad-mediated cytotoxicity, stimulation of a proinflammatory TME and activation of endogenous T cells to kill EOC cells or CAFs, Enadenotucirev has been modified to express a bispecific T-cell engager (BiTE) against epithelial cell adhesion molecule (EpCAM) [170] or fibroblast activation protein (FAP) [171], respectively, successfully reversing TME-mediated immunosuppression in ex vivo malignant ascites. Santos et al demonstrated that an Ad5/3- $\Delta 24$ expressing TNF $\alpha$ and IL2 under the control of the E2F promoter was able to reduce the suppressive cytokines and increase activation of CD4+ and CD8+ TILs in ex vivo tumor cultures independently of PD-L1 tumor expression, although at a lower level compared to other malignancies, highlighting the immunosuppressive TME in EOC [63, 172]. Huang et al confirmed that an oncolytic Ad5/35 armed with a SIRP $\alpha-F c$ 


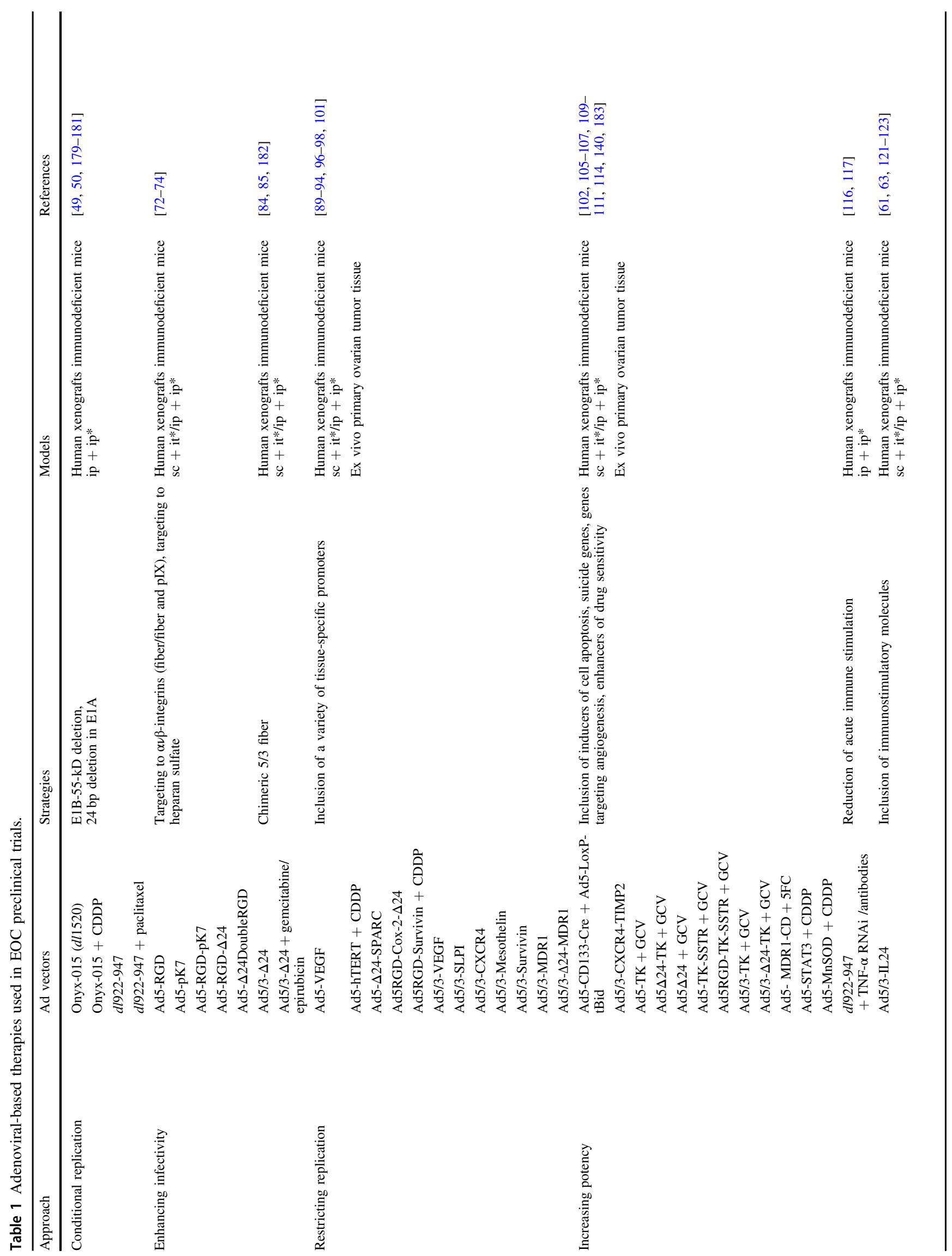




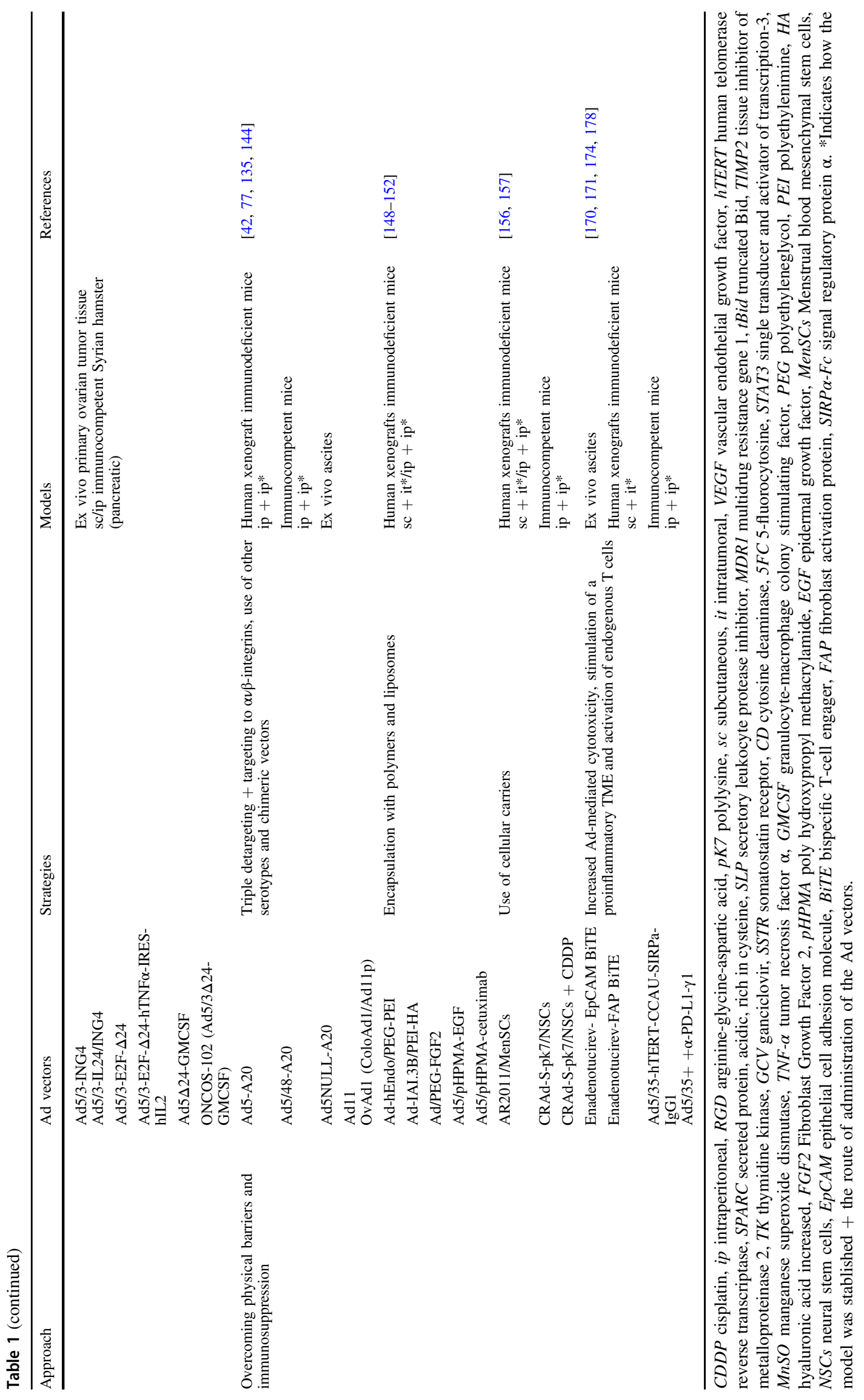




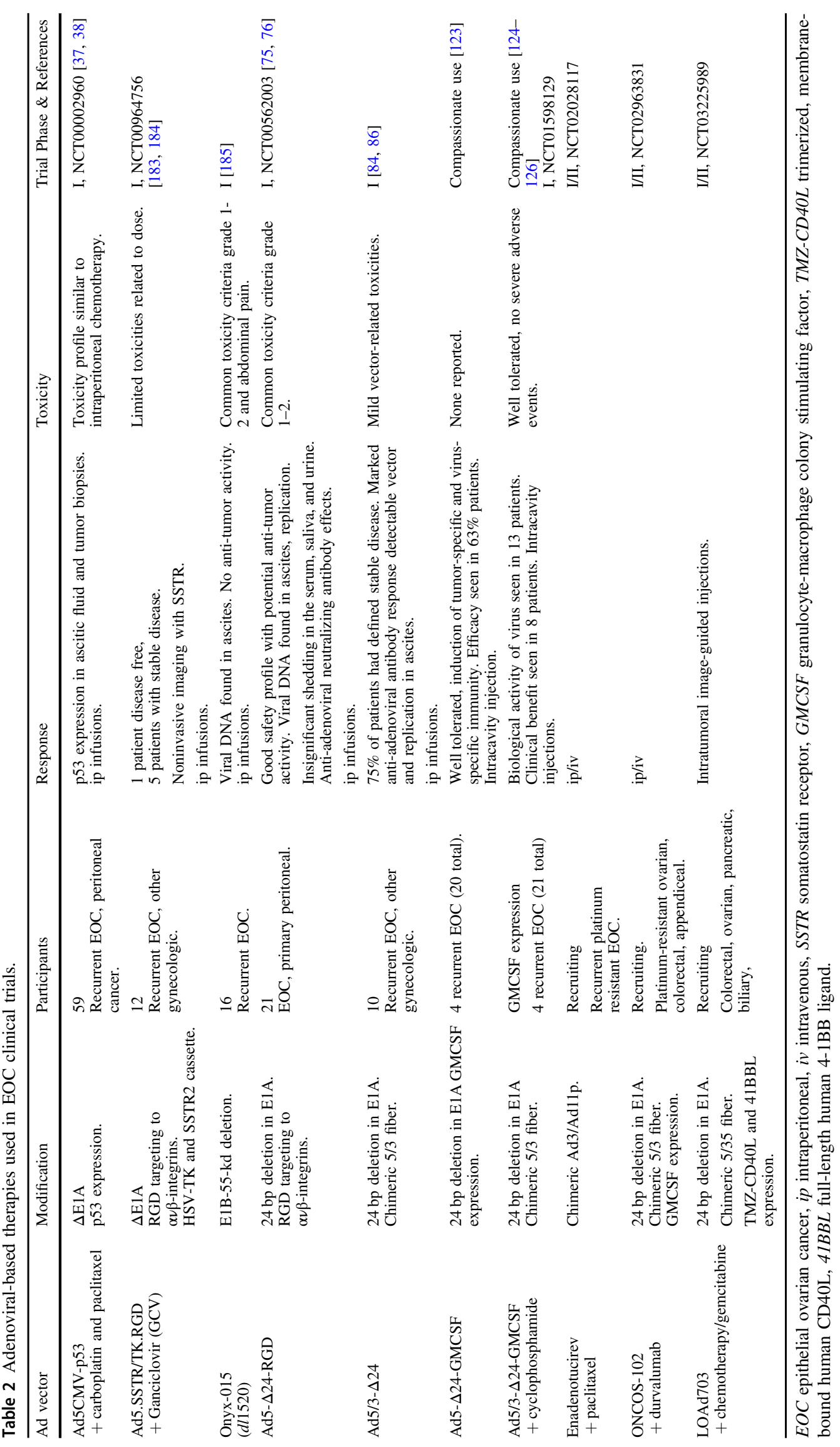


(signal regulatory protein $\alpha$ ) fusion gene expressed on macrophages demonstrated anti-tumor effect on a CD47positive SKOV3 xenograft model in the presence of immune population, indicating that CD47 blockade ('don'teat-me' signal for immune evasion) [173] successfully increased NK cells infiltration and macrophage mediated phagocytosis [174]. Instead of using antigen-dependent approaches, adoptive immunotherapy can be based on antigen-independent strategies, such as NK cells. Because NK cells in the TME are less cytotoxic and have an exhausted phenotype, different methods are being explored to potentiate their killing capacity [175]. Leung et al recently demonstrated that $d$ l922-947- and Enadenotucirevinfected EOC cells were able to activate human NK cells and augment their cytotoxicity in vitro in a contactdependent manner through different pathways [176]. Furthermore, the combination with TIGIT blockade, an inhibitory NK receptor associated with $\mathrm{T}$ cell exhaustion phenotypes [177], increased NK cytotoxicity. Considering that current prevention methods are limited for high-risk women with germline mutations, $\mathrm{Li}$ et al developed a method to genetically modify hematopoietic stem/progenitor cells (HSPC) in vivo based on an integrating Ad5/35 ++ vector expressing $\alpha$-PD-L1- $\gamma 1$ under the control of a miRNA regulation system that is activated only when HSPCs are recruited to and differentiated by the tumor into tumor-supporting cells [178]. They stablished a feasible in situ transduction strategy and demonstrated that intratumoral expression of $\alpha$-PD-L1- $\gamma 1$ early during tumor development successfully reduced primary tumor growth and prevention of recurrence.

\section{Summary and future directions}

In recent years, knowledge gained in terms of biology of both oncolytic Ads and EOC has enabled the development of more selective and potent CRAds (Table 1) able to overcome obstacles encountered in clinical trials (Table 2). While oncolytic Ads are promising tools, as they are able to kill tumor cells and stimulate an adaptive anti-tumor immune response, EOC is highly complex and its immunosuppressive microenvironment and heterogeneity among primary and metastatic tumors and ascites impairs Ad efficiency as single approach therapy. In order to create a more favorable TME, oncolytic Ads are the perfect match for combination with other emerging targeted strategies, such as immune checkpoint inhibitors or CAR-T cells. New advances should focus on finding the perfect balance between Ad replication and stimulation of the immune responses and improving regimens of administration, identification of novel unique ligands that can be efficiently targeted by incorporating singledomain antibodies (sdAbs) and fully understanding hostvirus interactions in complex preclinical models.
Funding This study was funded by the Department of Defense Ovarian Cancer Research Program (W81XWH-18-1-0063) and by the NIH (R01CA211096).

Author contributions R.G.-P. did literature research and wrote the paper. P.S.G. and D.T.C. provided supervision.

\section{Compliance with ethical standards}

Conflict of interest The authors declare that they have no conflict of interest.

Publisher's note Springer Nature remains neutral with regard to jurisdictional claims in published maps and institutional affiliations.

\section{References}

1. Global cancer statistics [database on the Internet]. 2008 [cited Apr 1, 2020).]. Available from: http://globocan.iarc.fr/Pages/fa ct_sheets_population.aspx.

2. Siegel RL, Miller KD, Jemal A. Cancer statistics, 2019. CA Cancer J Clin. 2019;69:7-34.

3. Prat J. Staging classification for cancer of the ovary, fallopian tube, and peritoneum. Int J Gynaecol Obstet. 2014;124:1-5.

4. Siegel RL, Miller KD, Jemal A. Cancer statistics, 2020. CA Cancer J Clin. 2020;70:7-30.

5. Lheureux S, Braunstein M, Oza AM. Epithelial ovarian cancer: evolution of management in the era of precision medicine. CA Cancer J Clin. 2019;69:280-304.

6. Menon U, Karpinskyj C, Gentry-Maharaj A. Ovarian cancer prevention and screening. Obstet Gynecol. 2018;131:909-27.

7. Otsuka I, Matsuura T. Screening and prevention for high-grade serous carcinoma of the ovary based on carcinogenesis-fallopian tube- and ovarian-derived tumors and incessant retrograde bleeding. Diagnostics. 2020;10:120.

8. Ledermann JA, Raja FA, Fotopoulou C, Gonzalez-Martin A, Colombo N, Sessa C. Newly diagnosed and relapsed epithelial ovarian carcinoma: ESMO Clinical Practice Guidelines for diagnosis, treatment and follow-up. Ann Oncol. 2013;24:vi24-32.

9. Marth C, Reimer D, Zeimet AG. Front-line therapy of advanced epithelial ovarian cancer: standard treatment. Ann Oncol. 2017;28:viii36-viii9.

10. Lheureux S, Gourley C, Vergote I, Oza AM. Epithelial ovarian cancer. Lancet. 2019;393:1240-53.

11. Reid BM, Permuth JB, Sellers TA. Epidemiology of ovarian cancer: a review. Cancer Biol Med 2017;14:9-32.

12. Vaughan S, Coward JI, Bast RC Jr., Berchuck A, Berek JS, Brenton JD, et al. Rethinking ovarian cancer: recommendations for improving outcomes. Nat Rev Cancer. 2011;11:719-25.

13. Karnezis AN, Cho KR, Gilks CB, Pearce CL, Huntsman DG. The disparate origins of ovarian cancers: pathogenesis and prevention strategies. Nat Rev Cancer. 2017;17:65-74.

14. Zhang S, Dolgalev I, Zhang T, Ran H, Levine DA, Neel BG. Both fallopian tube and ovarian surface epithelium are cells-oforigin for high-grade serous ovarian carcinoma. Nat Commun. 2019;10:5367.

15. Tan DS, Agarwal R, Kaye SB. Mechanisms of transcoelomic metastasis in ovarian cancer. Lancet Oncol. 2006;7:925-34.

16. Yeung TL, Leung CS, Yip KP, Au Yeung CL, Wong ST, Mok SC. Cellular and molecular processes in ovarian cancer metastasis. A review in the theme: cell and molecular processes in cancer metastasis. Am J Physiol Cell Physiol. 2015;309:C444-56. 
17. Cai Q, Yan $\mathrm{L}, \mathrm{Xu}$ Y. Anoikis resistance is a critical feature of highly aggressive ovarian cancer cells. Oncogene 2015;34:3315-24.

18. Lengyel E. Ovarian cancer development and metastasis. Am J Pathol. 2010;177:1053-64.

19. Ahmed N, Abubaker K, Findlay J, Quinn M. Epithelial mesenchymal transition and cancer stem cell-like phenotypes facilitate chemoresistance in recurrent ovarian cancer. Curr Cancer Drug Targets. 2010;10:268-78.

20. Naora H, Montell DJ. Ovarian cancer metastasis: integrating insights from disparate model organisms. Nat Rev Cancer. 2005;5:355-66.

21. Kenny HA, Kaur S, Coussens LM, Lengyel E. The initial steps of ovarian cancer cell metastasis are mediated by MMP-2 cleavage of vitronectin and fibronectin. J Clin Investig. 2008;118:1367-79.

22. Masoumi Moghaddam S, Amini A, Morris DL, Pourgholami MH. Significance of vascular endothelial growth factor in growth and peritoneal dissemination of ovarian cancer. Cancer Metastasis Rev. 2012;31:143-62.

23. Hollis RL, Gourley C. Genetic and molecular changes in ovarian cancer. Cancer Biol Med. 2016;13:236-47.

24. Kurman RJ. Origin and molecular pathogenesis of ovarian highgrade serous carcinoma. Ann Oncol. 2013;24:x16-21.

25. Markman M. Genomic-based therapy of gynecologic malignancies. Acta Med Acad. 2019;48:84-9.

26. Banerjee S, Kaye SB. New strategies in the treatment of ovarian cancer: current clinical perspectives and future potential. Clin Cancer Res. 2013;19:961-8.

27. Della Pepa C, Tonini G, Pisano C, Di Napoli M, Cecere SC, Tambaro R, et al. Ovarian cancer standard of care: are there real alternatives? Chin J Cancer. 2015;34:17-27.

28. Tsibulak I, Zeimet AG, Marth C. Hopes and failures in front-line ovarian cancer therapy. Crit Rev Oncol/Hematol. 2019;143:14-9.

29. Gupta S, Nag S, Aggarwal S, Rauthan A, Warrier N. Maintenance therapy for recurrent epithelial ovarian cancer: current therapies and future perspectives - a review. J Ovarian Res. 2019;12:103.

30. Áyen Á, Jiménez Martínez Y, Marchal JA, Boulaiz H. Recent progress in gene therapy for ovarian cancer. Int $\mathbf{J}$ Mol Sci. 2018;19:1930.

31. Wirth T, Ylä-Herttuala S. Gene therapy used in cancer treatment. Biomedicines 2014;2:149-62.

32. Crystal RG. Adenovirus: the first effective in vivo gene delivery vector. Hum Gene Ther. 2014;25:3-11.

33. Gao J, Mese K, Bunz O, Ehrhardt A. State-of-the-art human adenovirus vectorology for therapeutic approaches. FEBS Lett. 2019;593:3609-22.

34. Lee CS, Bishop ES, Zhang R, Yu X, Farina EM, Yan S, et al. Adenovirus-mediated gene delivery: potential applications for gene and cell-based therapies in the new era of personalized medicine. Genes Dis 2017;4:43-63.

35. Post DE, Khuri FR, Simons JW, Van, Meir EG. Replicative oncolytic adenoviruses in multimodal cancer regimens. Hum Gene Ther. 2003;14:933-46.

36. Liu TC, Galanis E, Kirn D. Clinical trial results with oncolytic virotherapy: a century of promise, a decade of progress. Nat Clin Pract Oncol. 2007;4:101-17.

37. Buller RE, Shahin MS, Horowitz JA, Runnebaum IB, Mahavni $\mathrm{V}$, Petrauskas S, et al. Long term follow-up of patients with recurrent ovarian cancer after Ad p53 gene replacement with SCH 58500. Cancer Gene Ther. 2002;9:567-72.

38. Buller RE, Runnebaum IB, Karlan BY, Horowitz JA, Shahin M, Buekers T, et al. A phase I/II trial of rAd/p53 (SCH 58500) gene replacement in recurrent ovarian cancer. Cancer Gene Ther. 2002;9:553-66

39. Modesitt SC, Ramirez P, Zu Z, Bodurka-Bevers D, Gershenson $\mathrm{D}$, Wolf JK. In vitro and in vivo adenovirus-mediated p53 and p16 tumor suppressor therapy in ovarian cancer: see the biology behind: ME Murphy, the battle between tumor suppressors: is gene therapy using p16INK4a more efficacious than p53 for treatment of ovarian carcinoma?. Clin Cancer Res. 2001;7:1765-72.

40. Von Gruenigen VE, Santoso JT, Coleman RL, Muller CY, Miller DS, Mathis JM. In vivostudies of adenovirus-based p53 gene therapy for ovarian cancer. Gynecologic Oncol. 1998;69:197-204.

41. Nielsen LL, Lipari P, Dell J, Gurnani M, Hajian G. Adenovirusmediated p53 gene therapy and paclitaxel have synergistic efficacy in models of human head and neck, ovarian, prostate, and breast cancer. Clin Cancer Res. 1998;4:835-46.

42. De Munck J, Binks A, McNeish IA, Aerts JL. Oncolytic virusinduced cell death and immunity: a match made in heaven? J Leukoc Biol. 2017;102:631-43.

43. Gujar S, Pol JG, Kim Y, Lee PW, Kroemer G. Antitumor benefits of antiviral immunity: an underappreciated aspect of oncolytic virotherapies. Trends Immunol. 2018;39:209-21.

44. Mathis JM, Stoff-Khalili MA, Curiel DT. Oncolytic adenoviruses - selective retargeting to tumor cells. Oncogene 2005;24:7775-91.

45. Jounaidi Y, Doloff JC, Waxman DJ. Conditionally replicating adenoviruses for cancer treatment. Curr Cancer Drug targets. 2007;7:285-301.

46. Kirn D. Replication-selective oncolytic adenoviruses: virotherapy aimed at genetic targets in cancer. Oncogene 2000;19:6660-9.

47. Baird SK, Aerts JL, Eddaoudi A, Lockley M, Lemoine NR, McNeish IA. Oncolytic adenoviral mutants induce a novel mode of programmed cell death in ovarian cancer. Oncogene 2008;27: 3081-90.

48. Cheng P-H, Wechman SL, McMasters KM, Zhou HS. Oncolytic replication of E1b-deleted adenoviruses. Viruses 2015;7: 5767-79.

49. Ingemarsdotter CK, Baird SK, Connell CM, Öberg D, Halldén G, McNeish IA. Low-dose paclitaxel synergizes with oncolytic adenoviruses via mitotic slippage and apoptosis in ovarian cancer. Oncogene 2010;29:6051-63.

50. Ingemarsdotter CK, Tookman LA, Browne A, Pirlo K, Cutts R, Chelela $\mathrm{C}$, et al. Paclitaxel resistance increases oncolytic adenovirus efficacy via upregulated CAR expression and dysfunctional cell cycle control. Mol Oncol. 2015;9:791-805.

51. Tookman LA, Browne AK, Connell CM, Bridge G, Ingemarsdotter CK, Dowson S, et al. RAD51 and BRCA2 enhance oncolytic adenovirus type 5 activity in ovarian cancer. Mol Cancer Res. 2016;14:44-55.

52. Bobbs AS, Cole JM, Cowden Dahl KD. Emerging and evolving ovarian cancer animal models. Cancer Growth Metastasis. 2015;8:29-36.

53. Magnotti E, Marasco WA. The latest animal models of ovarian cancer for novel drug discovery. Expert Opin Drug Discov. 2018;13:249-57.

54. Gitto SB, Kim H, Rafail S, Omran DK, Medvedev S, Kinose Y, et al. An autologous humanized patient-derived-xenograft platform to evaluate immunotherapy in ovarian cancer. Gynecol Oncol 2020;156:222-32.

55. Conejo-Garcia JR, Benencia F, Courreges MC, Kang E, Mohamed-Hadley A, Buckanovich RJ, et al. Tumor-infiltrating dendritic cell precursors recruited by a beta-defensin contribute to vasculogenesis under the influence of Vegf-A. Nat Med. 2004; 10:950-8.

56. Walton J, Blagih J, Ennis D, Leung E, Dowson S, Farquharson $\mathrm{M}$, et al. CRISPR/Cas9-mediated Trp53 and Brca2 knockout to generate improved murine models of ovarian high-grade serous carcinoma. Cancer Res. 2016;76:6118-29.

57. Ghaffari A, Peterson N, Khalaj K, Vitkin N, Robinson A, Francis JA, et al. STING agonist therapy in combination with PD-1 immune checkpoint blockade enhances response to carboplatin 
chemotherapy in high-grade serous ovarian cancer. Br J cancer. 2018;119:440-9.

58. Halldén G, Hill R, Wang Y, Anand A, Liu TC, Lemoine NR, et al. Novel immunocompetent murine tumor models for the assessment of replication-competent oncolytic adenovirus efficacy. Molecular therapy. J Am Soc Gene Ther. 2003;8:412-24.

59. Zhang L, Hedjran F, Larson C, Perez GL, Reid T. A novel immunocompetent murine model for replicating oncolytic adenoviral therapy. Cancer Gene Ther. 2015;22:17-22.

60. Young AM, Archibald KM, Tookman LA, Pool A, Dudek K, Jones $\mathrm{C}$, et al. Failure of translation of human adenovirus mRNA in murine cancer cells can be partially overcome by L4-100K expression in vitro and in vivo. Molecular therapy. J Am Soc Gene Ther. 2012;20:1676-88.

61. González-Pastor R, Ashshi AM, El-Shemi AG, Dmitriev IP, Kashentseva EA, Lu ZH, et al. Defining a murine ovarian cancer model for the evaluation of conditionally-replicative adenovirus (CRAd) virotherapy agents. J Ovarian Res. 2019;12:18.

62. Thomas MA, Spencer JF, La Regina MC, Dhar D, Tollefson AE, Toth K, et al. Syrian hamster as a permissive immunocompetent animal model for the study of oncolytic adenovirus vectors. Cancer Res. 2006;66:1270-6.

63. Santos JM, Heiniö C, Cervera-Carrascon V, Quixabeira DCA, Siurala M, Havunen R, et al. Oncolytic adenovirus shapes the ovarian tumor microenvironment for potent tumor-infiltrating lymphocyte tumor reactivity. J Immunother Cancer. 2020;8:e00188.

64. Russell WC. Adenoviruses: update on structure and function. J Gen Virol. 2009;90:1-20.

65. Yamamoto Y, Nagasato M, Yoshida T, Aoki K. Recent advances in genetic modification of adenovirus vectors for cancer treatment. Cancer Sci. 2017;108:831-7.

66. You Z, Fischer DC, Tong X, Hasenburg A, Aguilar-Cordova E, Kieback DG. Coxsackievirus-adenovirus receptor expression in ovarian cancer cell lines is associated with increased adenovirus transduction efficiency and transgene expression. Cancer Gene Ther. 2001;8:168-75.

67. Kim JS, Lee SH, Cho YS, Choi JJ, Kim YH, Lee JH. Enhancement of the adenoviral sensitivity of human ovarian cancer cells by transient expression of coxsackievirus and adenovirus receptor (CAR). Gynecol Oncol. 2002;85:260-5.

68. Zeimet A, Müller-Holzner E, Schuler A, Hartung G, Berger J, Hermann M, et al. Determination of molecules regulating gene delivery using adenoviral vectors in ovarian carcinomas. Gene Ther. 2002;9:1093-100.

69. Beatty MS, Curiel DT. Chapter two-Adenovirus strategies for tissue-specific targeting. Adv Cancer Res. 2012;115:39-67.

70. Dmitriev I, Krasnykh V, Miller CR, Wang M, Kashentseva E, Mikheeva G, et al. An adenovirus vector with genetically modified fibers demonstrates expanded tropism via utilization of a coxsackievirus and adenovirus receptor-independent cell entry mechanism. J Virol. 1998;72:9706-13.

71. Vanderkwaak TJ, Wang M, Gómez-Navarro J, Rancourt C, Dmitriev I, Krasnykh V, et al. An advanced generation of adenoviral vectors selectively enhances gene transfer for ovarian cancer gene therapy approaches. Gynecol Oncol. 1999;74:227-34.

72. Wu H, Han T, Lam JT, Leath CA, Dmitriev I, Kashentseva E, et al. Preclinical evaluation of a class of infectivity-enhanced adenoviral vectors in ovarian cancer gene therapy. Gene Ther. 2004; 11:874-8

73. Gamble LJ, Ugai H, Wang M, Borovjagin AV, Matthews QL. Therapeutic efficacy of an oncolytic adenovirus containing RGD ligand in minor capsid protein IX and Fiber, $\Delta 24$ DoubleRGD, in an ovarian cancer model. J Mol Biochem 2012;1:26-39.

74. Bauerschmitz GJ, Lam JT, Kanerva A, Suzuki K, Nettelbeck DM, Dmitriev I, et al. Treatment of ovarian cancer with a tropism modified oncolytic adenovirus. Cancer Res. 2002;62:1266-70.
75. Page JG, Tian B, Schweikart K, Tomaszewski J, Harris R, Broadt $\mathrm{T}$, et al. Identifying the safety profile of a novel infectivity-enhanced conditionally replicative adenovirus, Ad5delta24-RGD, in anticipation of a phase I trial for recurrent ovarian cancer. Am J Obstet Gynecol. 2007;196:389.e1-9. discussion.e9-10.

76. Kimball KJ, Preuss MA, Barnes MN, Wang M, Siegal GP, Wan $\mathrm{W}$, et al. A phase I study of a tropism-modified conditionally replicative adenovirus for recurrent malignant gynecologic diseases. Clin Cancer Res. 2010;16:5277-87.

77. Uusi-Kerttula H, Davies J, Coughlan L, Hulin-Curtis S, Jones R, Hanna L, et al. Pseudotyped $\alpha v \beta 6$ integrin-targeted adenovirus vectors for ovarian cancer therapies. Oncotarget 2016;7:27926-37.

78. Uusi-Kerttula H, Legut M, Davies J, Jones R, Hudson E, Hanna $\mathrm{L}$, et al. Incorporation of peptides targeting EGFR and FGFR1 into the adenoviral fiber knob domain and their evaluation as targeted cancer therapies. Hum Gene Ther. 2015;26:320-9.

79. Strauss R, Sova P, Liu Y, Li ZY, Tuve S, Pritchard D, et al. Epithelial phenotype confers resistance of ovarian cancer cells to oncolytic adenoviruses. Cancer Res. 2009;69:5115-25.

80. Wang H, Li ZY, Liu Y, Persson J, Beyer I, Möller T, et al. Desmoglein 2 is a receptor for adenovirus serotypes 3, 7, 11 and 14. Nat Med. 2011;17:96-104.

81. Kuryk L, Møller A-SW Chimeric oncolytic Ad5/3 virus replicates and lyses ovarian cancer cells through desmoglein-2 cell entry receptor. J Med Virol. 2020;92:1309-15.

82. Kanerva A, Mikheeva GV, Krasnykh V, Coolidge CJ, Lam JT, Mahasreshti PJ, et al. Targeting adenovirus to the serotype 3 receptor increases gene transfer efficiency to ovarian cancer cells. Clin Cancer Res. 2002;8:275-80.

83. Kanerva A, Wang M, Bauerschmitz GJ, Lam JT, Desmond RA, Bhoola SM, et al. Gene transfer to ovarian cancer versus normal tissues with fiber-modified adenoviruses. Mol Ther: J Am Soc Gene Ther. 2002;5:695-704.

84. Kanerva A, Zinn KR, Chaudhuri TR, Lam JT, Suzuki K, Uil TG, et al. Enhanced therapeutic efficacy for ovarian cancer with a serotype 3 receptor-targeted oncolytic adenovirus. Mol Ther: J Am Soc Gene Ther. 2003;8:449-58.

85. Raki M, Kanerva A, Ristimaki A, Desmond RA, Chen DT, Ranki T, et al. Combination of gemcitabine and Ad5/3- $\Delta 24$, a tropism modified conditionally replicating adenovirus, for the treatment of ovarian cancer. Gene Ther. 2005;12:1198-205.

86. Kim KH, Dmitriev IP, Saddekni S, Kashentseva EA, Harris RD, Aurigemma R, et al. A phase I clinical trial of Ad5/3- $\Delta 24$, a novel serotype-chimeric, infectivity-enhanced, conditionallyreplicative adenovirus (CRAd), in patients with recurrent ovarian cancer. Gynecol Oncol. 2013;130:518-24.

87. Fleischli C, Sirena D, Lesage G, Havenga MJ, Cattaneo R, Greber UF, et al. Species B adenovirus serotypes 3, 7, 11 and 35 share similar binding sites on the membrane cofactor protein CD46 receptor. J Gen Virol. 2007;88:2925-34.

88. Hulin-Curtis SL, Uusi-Kerttula H, Jones R, Hanna L, Chester JD, Parker AL. Evaluation of CD46 re-targeted adenoviral vectors for clinical ovarian cancer intraperitoneal therapy. Cancer Gene Ther. 2016;23:229-34.

89. Kanerva A, Bauerschmitz GJ, Yamamoto M, Lam JT, Alvarez $\mathrm{RD}$, Siegal GP, et al. A cyclooxygenase-2 promoter-based conditionally replicating adenovirus with enhanced infectivity for treatment of ovarian adenocarcinoma. Gene Ther. 2004;11:552-9.

90. Lam JT, Kanerva A, Bauerschmitz GJ, Takayama K, Suzuki K, Yamamoto $\mathrm{M}$, et al. Inter-patient variation in efficacy of five oncolytic adenovirus candidates for ovarian cancer therapy. $\mathrm{J}$ Gene Med. 2004;6:1333-42.

91. Bauerschmitz GJ, Guse K, Kanerva A, Menzel A, Herrmann I, Desmond RA, et al. Triple-targeted oncolytic adenoviruses featuring the $\operatorname{cox} 2$ promoter, E1A transcomplementation, and 
serotype chimerism for enhanced selectivity for ovarian cancer cells. Mol Ther: J Am Soc Gene Ther. 2006;14:164-74.

92. Rein DT, Breidenbach M, Kirby TO, Han T, Siegal GP, Bauerschmitz GJ, et al. A fiber-modified, secretory leukoprotease inhibitor promoter-based conditionally replicating adenovirus for treatment of ovarian cancer. Clin Cancer Res. 2005;11:1327-35.

93. Takakura M, Nakamura M, Kyo S, Hashimoto M, Mori N, Ikoma $\mathrm{T}$, et al. Intraperitoneal administration of telomerasespecific oncolytic adenovirus sensitizes ovarian cancer cells to cisplatin and affects survival in a xenograft model with peritoneal dissemination. Cancer Gene Ther. 2010;17:11-9.

94. Rein DT, Volkmer A, Beyer IM, Curiel DT, Janni W, Dragoi A, et al. Treatment of chemotherapy resistant ovarian cancer with a MDR1 targeted oncolytic adenovirus. Gynecol Oncol. 2011;123: 138-46.

95. Zhu ZB, Makhija SK, Lu B, Wang M, Kaliberova L, Liu B, et al. Transcriptional targeting of adenoviral vector through the CXCR4 tumor-specific promoter. Gene Ther. 2004;11:645-8.

96. Rocconi RP, Zhu ZB, Stoff-Khalili M, Rivera AA, Lu B, Wang $\mathrm{M}$, et al. Treatment of ovarian cancer with a novel dual targeted conditionally replicative adenovirus (CRAd). Gynecol Oncol. 2007;105:113-21.

97. Zhu ZB, Lu B, Park M, Makhija SK, Numnum TM, Kendrick JE, et al. Development of an optimized conditionally replicative adenoviral agent for ovarian cancer. Int J Oncol. 2008;32: 1179-88.

98. Zhang B, Liu Y, Zhang P, Wei Y, Yin X, Zheng J. A novel CRAd in combination with cisplatin enhanced the antitumor efficacy in ovarian cancer. Int J Gynecol Cancer 2011;21:1540-6.

99. Ko SY, Naora H. Therapeutic strategies for targeting the ovarian tumor stroma. World J Clin Cases. 2014;2:194-200.

100. Köbel M, Turbin D, Kalloger SE, Gao D, Huntsman DG, Gilks CB. Biomarker expression in pelvic high-grade serous carcinoma: comparison of ovarian and omental sites. Int $\mathrm{J}$ Gynecol Pathol. 2011;30:366-71.

101. Lopez MV, Rivera AA, Viale DL, Benedetti L, Cuneo N, Kimball KJ, et al. A tumor-stroma targeted oncolytic adenovirus replicated in human ovary cancer samples and inhibited growth of disseminated solid tumors in mice. Mol Ther. 2012;20: 2222-33.

102. Long Q, Yang R, Lu W, Zhu W, Zhou J, Zheng C, et al. Adenovirus-mediated truncated Bid overexpression induced by the Cre/LoxP system promotes the cell apoptosis of CD133+ ovarian cancer stem cells. Oncol Rep. 2017;37:155-62.

103. Bett AJ, Prevec L, Graham FL. Packaging capacity and stability of human adenovirus type 5 vectors. J Virol. 1993;67:5911-21.

104. Cody JJ, Douglas JT. Armed replicating adenoviruses for cancer virotherapy. Cancer Gene Ther. 2009;16:473-88.

105. Wildner O, Morris JC. The role of the E1B $55 \mathrm{kDa}$ gene product in oncolytic adenoviral vectors expressing herpes simplex virustk: assessment of antitumor efficacy and toxicity. Cancer Res. 2000;60:4167-74.

106. Hakkarainen T, Hemminki A, Curiel DT, Wahlfors J. A conditionally replicative adenovirus that codes for a TK-GFP fusion protein (Ad5Delta24TK-GFP) for evaluation of the potency of oncolytic virotherapy combined with molecular chemotherapy. Int J Mol Med. 2006;18:751-9.

107. Raki M, Hakkarainen T, Bauerschmitz GJ, Särkioja M, Desmond RA, Kanerva A, et al. Utility of TK/GCV in the context of highly effective oncolysis mediated by a serotype 3 receptor targeted oncolytic adenovirus. Gene Ther. 2007;14:1380-8.

108. Akbulut H, Zhang L, Tang Y, Deisseroth A. Cytotoxic effect of replication-competent adenoviral vectors carrying L-plastin promoter regulated E1A and cytosine deaminase genes in cancers of the breast, ovary and colon. Cancer Gene Ther. 2003;10:388-95.
109. Lu S, Wang X, Xiao L, Cai L, Zhang Y, Wang H, et al. Gene therapy for ovarian cancer using adenovirus-mediated transfer of cytosine deaminase gene and uracil phosphoribosyltransferase gene directed by MDR1 promoter. Cancer Biol Ther 2007;6:397-404.

110. Han Z, Hong Z, Gao Q, Chen C, Hao Z, Ji T, et al. A potent oncolytic adenovirus selectively blocks the STAT3 signaling pathway and potentiates cisplatin antitumor activity in ovarian cancer. Hum Gene Ther. 2012;23:32-45.

111. Wang S, Shu J, Chen L, Chen X, Zhao J, Li S, et al. Synergistic suppression effect on tumor growth of ovarian cancer by combining cisplatin with a manganese superoxide dismutase-armed oncolytic adenovirus. OncoTargets Ther 2016;9:6381-8.

112. Sauthoff H, Hu J, Maca C, Goldman M, Heitner S, Yee H, et al. Intratumoral spread of wild-type adenovirus is limited after local injection of human xenograft tumors: virus persists and spreads systemically at late time points. Hum Gene Ther. 2003;14: 425-33.

113. Cho A, Howell VM, Colvin EK. The extracellular matrix in epithelial ovarian cancer - a piece of a puzzle. Front Oncol. 2015;5:245-.

114. Yang SW, Cody JJ, Rivera AA, Waehler R, Wang M, Kimball $\mathrm{KJ}$, et al. Conditionally replicating adenovirus expressing TIMP2 for ovarian cancer therapy. Clin Cancer Res. 2011;17: 538-49.

115. Ashshi AM, El-Shemi AG, Dmitriev IP, Kashentseva EA, Curiel DT. Combinatorial strategies based on CRAd-IL24 and CRAdING4 virotherapy with anti-angiogenesis treatment for ovarian cancer. J Ovarian Res. 2016;9:38.

116. Salako MA, Kulbe H, Ingemarsdotter CK, Pirlo KJ, Williams $\mathrm{SL}$, Lockley $\mathrm{M}$, et al. Inhibition of the inflammatory cytokine $\mathrm{TNF}-\alpha$ increases adenovirus activity in ovarian cancer via modulation of cIAP1/2 expression. Mol Ther: J Am Soc Gene Ther. 2011;19:490-9.

117. Browne A, Tookman LA, Ingemarsdotter CK, Bouwman RD, Pirlo K, Wang Y, et al. Pharmacological inhibition of $\beta 3$ integrin reduces the inflammatory toxicities caused by oncolytic adenovirus without compromising anticancer activity. Cancer Res. 2015;75:2811-21.

118. Taipale K, Tähtinen S, Havunen R, Koski A, Liikanen I, Pakarinen $\mathrm{P}$, et al. Interleukin 8 activity influences the efficacy of adenoviral oncolytic immunotherapy in cancer patients. Oncotarget 2018;9:6320-35.

119. Chen J, Zajac AJ, McPherson SA, Hsu HC, Yang P, Wu Q, et al. Primary adenovirus-specific cytotoxic $\mathrm{T}$ lymphocyte response occurs after viral clearance and liver enzyme elevation. Gene Ther. 2005;12:1079-88.

120. Li X, Wang P, Li H, Du X, Liu M, Huang Q, et al. The efficacy of oncolytic adenovirus is mediated by T-cell responses against virus and tumor in Syrian hamster model. Clin Cancer Res. 2017;23:239-49.

121. Havunen R, Siurala M, Sorsa S, Grönberg-Vähä-Koskela S, Behr M, Tähtinen S, et al. Oncolytic adenoviruses armed with tumor necrosis factor alpha and interleukin-2 enable successful adoptive cell therapy. Mol Ther oncolytics 2017;4:77-86.

122. Heiniö C, Havunen R, Santos J, de Lint K, Cervera-Carrascon V, Kanerva A, et al. TNFa and IL2 encoding oncolytic Adenovirus activates pathogen and danger-associated immunological signaling. Cells. 2020;9:798.

123. Cerullo V, Pesonen S, Diaconu I, Escutenaire S, Arstila PT, Ugolini M, et al. Oncolytic adenovirus coding for granulocyte macrophage colony-stimulating factor induces antitumoral immunity in cancer patients. Cancer Res. 2010;70:4297-309.

124. Ranki T, Pesonen S, Hemminki A, Partanen K, Kairemo K, Alanko T, et al. Phase I study with ONCOS-102 for the treatment of solid tumors - an evaluation of clinical response and exploratory analyses of immune markers. J Immunother Cancer 2016;4:17. 
125. Vassilev L, Ranki T, Joensuu T, Jäger E, Karbach J, Wahle C, et al. Repeated intratumoral administration of ONCOS-102 leads to systemic antitumor CD8(+) T-cell response and robust cellular and transcriptional immune activation at tumor site in a patient with ovarian cancer. Oncoimmunology 2015;4:e1017702.

126. Koski A, Kangasniemi L, Escutenaire S, Pesonen S, Cerullo V, Diaconu I, et al. Treatment of cancer patients with a serotype 5/3 chimeric oncolytic adenovirus expressing GMCSF. Mol Ther: J Am Soc Gene Ther 2010;18:1874-84.

127. Mahasreshti PJ, Kataram M, Wang MH, Stockard CR, Grizzle WE, Carey D, et al. Intravenous delivery of adenovirus-mediated soluble FLT-1 results in liver toxicity. Clin Cancer Res. 2003;9:2701-10.

128. Jönsson F, Kreppel F. Barriers to systemic application of virusbased vectors in gene therapy: lessons from adenovirus type 5 . Virus Genes. 2017;53:692-9.

129. Kim S, Kim B, Song YS. Ascites modulates cancer cell behavior, contributing to tumor heterogeneity in ovarian cancer. Cancer Sci. 2016;107:1173-8.

130. Penet M-F, Krishnamachary B, Wildes FB, Mironchik Y, Hung $\mathrm{C}-\mathrm{F}, \mathrm{Wu} \mathrm{TC}$, et al. Ascites volumes and the ovarian cancer microenvironment. Front Oncol. 2018;8:595-.

131. Kipps E, Tan DS, Kaye SB. Meeting the challenge of ascites in ovarian cancer: new avenues for therapy and research. Nat Rev Cancer. 2013;13:273-82.

132. Blackwell JL, Li H, Gomez-Navarro J, Dmitriev I, Krasnykh V, Richter CA, et al. Using a tropism-modified adenoviral vector to circumvent inhibitory factors in ascites fluid. Hum Gene Ther 2000;11:1657-69.

133. Stallwood Y, Fisher KD, Gallimore PH, Mautner V. Neutralisation of adenovirus infectivity by ascitic fluid from ovarian cancer patients. Gene Ther. 2000;7:637-43.

134. Hemminki A, Wang M, Desmond RA, Strong TV, Alvarez RD, Curiel DT. Serum and ascites neutralizing antibodies in ovarian cancer patients treated with intraperitoneal adenoviral gene therapy. Hum Gene Ther. 2002;13:1505-14.

135. Thoma C, Bachy V, Seaton P, Green NK, Greaves DR, Klavinskis $\mathrm{L}$, et al. Adenovirus serotype 11 causes less long-term intraperitoneal inflammation than serotype 5: implications for ovarian cancer therapy. Virology 2013;447:74-83.

136. Alba R, Bradshaw AC, Coughlan L, Denby L, McDonald RA, Waddington SN, et al. Biodistribution and retargeting of FXbinding ablated adenovirus serotype 5 vectors. Blood 2010;116: 2656-64.

137. Atasheva S, Shayakhmetov DM. Adenovirus sensing by the immune system. Curr Opin Virol. 2016;21:109-13.

138. Allen RJ, Byrnes AP. Interaction of adenovirus with antibodies, complement, and coagulation factors. FEBS Lett. 2019;593:3449-60.

139. Akiyama M, Thorne S, Kirn D, Roelvink PW, Einfeld DA, King $\mathrm{CR}$, et al. Ablating CAR and integrin binding in adenovirus vectors reduces nontarget organ transduction and permits sustained bloodstream persistence following intraperitoneal administration. Mol Ther. 2004;9:218-30.

140. Hemminki A, Zinn KR, Liu B, Chaudhuri TR, Desmond RA, Rogers BE, et al. In vivo molecular chemotherapy and noninvasive imaging with an infectivity-enhanced adenovirus. J Natl Cancer Inst. 2002;94:741-9.

141. Short JJ, Rivera AA, Wu H, Walter MR, Yamamoto M, Mathis JM, et al. Substitution of adenovirus serotype 3 hexon onto a serotype 5 oncolytic adenovirus reduces factor $\mathrm{X}$ binding, decreases liver tropism, and improves antitumor efficacy. Mol Cancer Ther. 2010;9:2536-44.

142. Barry MA, Rubin JD, Lu SC Retargeting adenoviruses for therapeutic applications and vaccines. FEBS Lett. 2020;594: $1918-46$.
143. Uusi-Kerttula H, Davies JA, Thompson JM, Wongthida P, Evgin L, Shim KG, et al. Ad5(NULL)-A20: a tropism-modified, $\alpha v \beta 6$ integrin-selective oncolytic adenovirus for epithelial ovarian cancer therapies. Clin Cancer Res. 2018;24:4215-24.

144. Kuhn I, Bauzon M, Green N, Seymour L, Fisher K, Hermiston T. OvAd1, a novel, potent, and selective chimeric oncolytic virus developed for ovarian cancer by 3D-directed evolution. Mol Ther Oncolytics. 2017;4:55-66.

145. Sun Y, Lv X, Ding P, Wang L, Sun Y, Li S, et al. Exploring the functions of polymers in adenovirus-mediated gene delivery: Evading immune response and redirecting tropism. Acta Biomaterialia. 2019;97:93-104.

146. Choi JW, Lee YS, Yun CO, Kim SW. Polymeric oncolytic adenovirus for cancer gene therapy. J Controlled Release. 2015;219:181-91.

147. Kim J, Kim PH, Kim SW, Yun CO. Enhancing the therapeutic efficacy of adenovirus in combination with biomaterials. Biomaterials 2012;33:1838-50.

148. Yang L, Wang L, Su XQ, Wang L, Chen XC, Li D, et al. Suppression of ovarian cancer growth via systemic administration with liposome-encapsulated adenovirus-encoding endostatin. Cancer Gene Ther. 2010;17:49-57.

149. Yoshihara C, Hamada K, Koyama Y. Preparation of a novel adenovirus formulation with artificial envelope of multilayer polymer-coatings: therapeutic effect on metastatic ovarian cancer. Oncol Rep. 2010;23:733-8.

150. Lanciotti J, Song A, Doukas J, Sosnowski B, Pierce G, Gregory $\mathrm{R}$, et al. Targeting adenoviral vectors using heterofunctional polyethylene glycol FGF2 conjugates. Mol Ther: J Am Soc Gene Ther. 2003;8:99-107.

151. Morrison J, Briggs SS, Green N, Fisher K, Subr V, Ulbrich K, et al. Virotherapy of ovarian cancer with polymer-cloaked adenovirus retargeted to the epidermal growth factor receptor. Mol Ther: J Am Soc Gene Ther. 2008;16:244-51.

152. Morrison J, Briggs SS, Green NK, Thoma C, Fisher KD, Kehoe $\mathrm{S}$, et al. Cetuximab retargeting of adenovirus via the epidermal growth factor receptor for treatment of intraperitoneal ovarian cancer. Hum Gene Ther. 2009;20:239-51.

153. Li Z, Fan D, Xiong D. Mesenchymal stem cells as delivery vectors for anti-tumor therapy. Stem Cell Investig. 2015;2:6-.

154. Reagan MR, Kaplan DL. Concise review: Mesenchymal stem cell tumor-homing: detection methods in disease model systems. Stem Cells. 2011;29:920-7.

155. Kuroki LM, Jin X, Dmitriev IP, Kashentseva EA, Powell MA, Mutch DG, et al. Adenovirus platform enhances transduction efficiency of human mesenchymal stem cells: An opportunity for cellular carriers of targeted TRAIL-based TR3 biologics in ovarian cancer. PloS ONE. 2017;12:e0190125.

156. Dembinski JL, Spaeth EL, Fueyo J, Gomez-Manzano C, Studeny $\mathrm{M}$, Andreeff $\mathrm{M}$, et al. Reduction of nontarget infection and systemic toxicity by targeted delivery of conditionally replicating viruses transported in mesenchymal stem cells. Cancer Gene Ther. 2010;17:289-97.

157. Alfano AL, Nicola Candia A, Cuneo N, Guttlein LN, Soderini A, Rotondaro C, et al. Oncolytic adenovirus-loaded menstrual blood stem cells overcome the blockade of viral activity exerted by ovarian cancer ascites. Mol Ther oncolytics 2017;6:31-44.

158. Mooney R, Majid AA, Batalla-Covello J, Machado D, Liu X, Gonzaga J, et al. Enhanced delivery of oncolytic adenovirus by neural stem cells for treatment of metastatic ovarian cancer. Mol Ther oncolytics 2019;12:79-92.

159. Doo DW, Norian LA, Arend RC. Checkpoint inhibitors in ovarian cancer: a review of preclinical data. Gynecologic Oncol Rep. 2019;29:48-54. 
160. Zhu X, Lang J. Programmed death-1 pathway blockade produces a synergistic antitumor effect: combined application in ovarian cancer. J gynecologic Oncol 2017;28:e64.

161. Farolfi A, Gurioli G, Fugazzola P, Burgio SL, Casanova C, Ravaglia $G$, et al. Immune system and DNA repair defects in ovarian cancer: implications for locoregional approaches. Int $\mathrm{J}$ Mol Sci. 2019;20:2569.

162. Rodriguez GM, Galpin KJC, McCloskey CW, Vanderhyden BC The tumor microenvironment of epithelial ovarian cancer and its influence on response to immunotherapy. Cancers. 2018;10:242.

163. Baci D, Bosi A, Gallazzi M, Rizzi M, Noonan DM, Poggi A, et al. The ovarian cancer tumor immune microenvironment (TIME) as target for therapy: a focus on innate immunity cells as therapeutic effectors. Int J Mol Sci. 2020;21:3125.

164. Meza-Perez S, Randall TD. Immunological functions of the omentum. Trends Immunol. 2017;38:526-36.

165. Horikawa N, Abiko K, Matsumura N, Hamanishi J, Baba T, Yamaguchi K, et al. Expression of vascular endothelial growth factor in ovarian cancer inhibits tumor immunity through the accumulation of myeloid-derived suppressor cells. Clin Cancer Res. 2017;23:587-99.

166. Ghisoni E, Imbimbo M, Zimmermann S, Valabrega G. Ovarian cancer immunotherapy: turning up the heat. Int $\mathrm{J}$ Mol Sci. 2019;20:2927.

167. Borella F, Ghisoni E, Giannone G, Cosma S, Benedetto C, Valabrega $\mathrm{G}$, et al. Immune checkpoint inhibitors in epithelial ovarian cancer: an overview on efficacy and future perspectives. Diagnostics 2020;10:146.

168. Harrington K, Freeman DJ, Kelly B, Harper J, Soria JC. Optimizing oncolytic virotherapy in cancer treatment. Nat Rev Drug Discov. 2019;18:689-706.

169. Cervera-Carrascon V, Havunen R, Hemminki A. Oncolytic adenoviruses: a game changer approach in the battle between cancer and the immune system. Expert Opin Biol Ther. 2019;19:443-55.

170. Freedman JD, Hagel J, Scott EM, Psallidas I, Gupta A, Spiers L, et al. Oncolytic adenovirus expressing bispecific antibody targets T-cell cytotoxicity in cancer biopsies. EMBO Mol Med. 2017;9:1067-87.

171. Freedman JD, Duffy MR, Lei-Rossmann J, Muntzer A, Scott EM, Hagel J, et al. An oncolytic virus expressing a T-cell engager simultaneously targets cancer and immunosuppressive stromal cells. Cancer Res. 2018;78:6852-65.

172. Abiko K, Matsumura N, Hamanishi J, Horikawa N, Murakami $\mathrm{R}$, Yamaguchi K, et al. IFN- $\gamma$ from lymphocytes induces PD-L1 expression and promotes progression of ovarian cancer. $\mathrm{Br} \mathrm{J}$ cancer. 2015;112:1501-9.

173. Tong B, Wang M. CD47 is a novel potent immunotherapy target in human malignancies: current studies and future promises. Future Oncol. 2018;14:2179-88.
174. Huang Y, Lv SQ, Liu PY, Ye ZL, Yang H, Li LF, et al. A SIRP $\alpha-F c$ fusion protein enhances the antitumor effect of oncolytic adenovirus against ovarian cancer. Mol Oncol 2020;14:657-68.

175. Hoogstad-van Evert JS, Bekkers R, Ottevanger N, Jansen JH, Massuger L, Dolstra $\mathrm{H}$ Harnessing natural killer cells for the treatment of ovarian cancer. Gynecol Oncol. 2020;175:P810-6.

176. Leung EYL, Ennis DP, Kennedy PR, Hansell C, Dowson S, Farquharson M, et al. NK cells augment oncolytic adenovirus cytotoxicity in ovarian cancer. Mol Ther oncolytics 2020;16: 289-301.

177. Chen F, Xu Y, Chen Y, Shan S. TIGIT enhances CD4(+) regulatory T-cell response and mediates immune suppression in a murine ovarian cancer model. Cancer Med 2020;9:3584-91.

178. Li C, Course MM, McNeish IA, Drescher CW, Valdmanis PN, Lieber A. Prophylactic in vivo hematopoietic stem cell gene therapy with an immune checkpoint inhibitor reverses tumor growth in syngeneic mouse tumor models. Cancer Res 2020;80:549-60.

179. Heise C, Ganly I, Kim Y, Sampson-Johannes A, Brown R, Kirn D. Efficacy of a replication-selective adenovirus against ovarian carcinomatosis is dependent on tumor burden, viral replication and p53 status. Gene Ther. 2000;7:1925-9.

180. Heise C, Lemmon M, Kirn D. Efficacy with a replicationselective adenovirus plus cisplatin-based chemotherapy: dependence on sequencing but not p53 functional status or route of administration. Clin Cancer Res. 2000;6:4908-14.

181. Lockley M, Fernandez M, Wang Y, Li NF, Conroy S, Lemoine $\mathrm{N}$, et al. Activity of the adenoviral E1A deletion mutant d1922947 in ovarian cancer: comparison with E1A wild-type viruses, bioluminescence monitoring, and intraperitoneal delivery in icodextrin. Cancer Res. 2006;66:989-98.

182. Raki M, Särkioja M, Desmond RA, Chen D-T, Bützow R, Hemminki A, et al. Oncolytic adenovirus Ad5/3- $\Delta 24$ and chemotherapy for treatment of orthotopic ovarian cancer. Gynecol Oncol. 2008;108:166-72.

183. Hemminki A, Belousova N, Zinn KR, Liu B, Wang M, Chaudhuri TR, et al. An adenovirus with enhanced infectivity mediates molecular chemotherapy of ovarian cancer cells and allows imaging of gene expression. Mol Ther. 2001;4:223-31.

184. Kim KH, Dmitriev I, O’Malley JP, Wang M, Saddekni S, You Z, et al. A phase I clinical trial of Ad5.SSTR/TK.RGD, a novel infectivity-enhanced bicistronic adenovirus, in patients with recurrent gynecologic cancer. Clin Cancer Res. 2012;18:3440-51.

185. Vasey PA, Shulman LN, Campos S, Davis J, Gore M, Johnston $\mathrm{S}$, et al. Phase I trial of intraperitoneal injection of the E1B-55kd-gene-deleted adenovirus ONYX-015 (d11520) given on days 1 through 5 every 3 weeks in patients with recurrent/refractory epithelial ovarian cancer. J Clin Oncol. 2002;20:1562-9. 